\title{
La industria del cemento dentro de la problemática de la contaminación atmosférica
}

ALFONSO ENSEÑAT DE VILLALONCA, Subdirector Ceneral del Medio Ambiente Industriall

Venir a hablar del cemento en el "Santuario del cemento" como muy bien podría llamarse a este Instituto Eduardo Torroja, es una osadía sólo permisible a los alquimistas de este preciado material de construcción o a los tecnólogos que dominan y perfeccionan cada día los procesos de producción y amplían el campo de sus aplicaciones. Y más destacable es aún el atrevimiento del conferenciante que acude a unas jornadas que congregan a casi todos los magnates y sabios del cemento.

No obstante, no he titubeado en aceptar la amable invitación del Profesor Arredondo, en su calidad de Presidente del Comité Ejecutivo de Colcem-76, ya que, según parece, este Coloquio no sólo pretende presentar y discutir las innovaciones tecnológicas conseguidas desde la anterior edición de estos Coloquios en este sector industrial, sino también repasar los problemas que afectan, perturban o influyen en su normal desarrollo.

Desgraciadamente, por razón de mi cargo en la Administración, me encuentro incluido entre los conferenciantes que deben aludir a los problemas del sector y no a sus importantes progresos.

Podríamos decir que un grupo de conferenciantes - los investigadores- vienen a hablarnos del futuro del sector desde el punto de vista de los avances tecnológicos, lo que conlleva el triunfalismo de supuestas mejoras de productividad, ahorros de energía y, en definitiva, reducción de costos de producción. Otro grupo de conferenciantes -que de alguna manera estamos ligados a la Administración Pública- venimos invitados, digamos, a justificar los actos administrativos que de alguna manera afectan en forma aparentemente desfavorable a la buena marcha del sector productivo, actos que, por otra parte, dimanan de una política que en su día el Gobierno trazó y mereció el refrendo del más alto órgano legislativo del país.

Mi exposición pretende simplemente recordar algunos conceptos y aclarar otros contenidos dentro del marco de la política ambiental, en su vertiente de protección del ambiente atmosférico. Procuraré no caer en la trampa ni en la tentación de salirme del terreno que me ha sido confiado, ya que la alta cualificación de las personalidades aquí congregadas convertirían en ridícula pedantería cualquier infracción de dicha regla. 
Dividiré la exposición en tres partes:

En la primera trataré del problema general de la contaminación atmosférica en la industria del cemento; en la segunda expondré los resultados de una encuesta realizada cerca de este sector sobre la misma temática; y en la tercera me referiré a la legislación vigente en nuestro país sobre protección del medio ambiente atmosférico.

\section{Problema general de la contaminación atmosférica en la industria del cemento}

Las partículas sólidas constituyen, con mucho, el principal contaminante emitido a la atmósfera por la industria del cemento. Aunque no son realmente nocivas por su ausencia de toxicidad, son frecuentemente causa de molestias para la población circundante y puede producir perjuicios en la agricultura al cubrir las hojas de las plantas de una finísima capa de polvo.

Es interesante conocer el análisis granulométrico de los polvos emitidos por una planta cementera, ya que de ella dependen los perjuicios que de su acción sobre los seres vivos puede derivarse.

Un $7 \%$ aproximadamente de las partículas son pesadas, es decir mayores de 60 micras, lo que las configura como partículas sedimentables, que caerán muy cerca de la planta, con casi independencia de la altura de la chimenea.

Alrededor de un $25 \%$ de las partículas se encuentran entre 1 y 10 micras. Dichas partículas serán transportadas a muy largas distancias.

Sólo un $3 \%$ de las partículas son submicrónicas. Este tipo de partículas sería el más perjudicial si se encontrara muy concentrado al nivel del suelo, ya que puede producir neumoconiosis en los individuos sometidos a larga exposición ante los mismos. Afortunadamente este polvo es el que se transporta a más largas distancias y llega a tierra en concentración inapreciable.

Los focos de emisión de polvos en una fábrica de cemento son muy numerosos. La cantera constituye ya el primer foco, pues es en donde realmente empieza el ciclo de producción del cemento. Las emisiones de polvos se producen en el arranque de la piedra con martillos neumáticos, en la caída del frente de corte - muy variable según la humedad de la tierra- y en el machaqueo primario (granos de 20 a $30 \mathrm{~mm}$ ). En este último caso, el desempolvado puede llevarse a cabo por pulverización de agua o por medio de filtros de mangas o ambos sistemas aplicados a la vez.

Ya en la planta, el machaqueo secundario de la roca, llevado a cabo en una, dos, o tres etapas, es nueva fuente de generación de polvo.

La producción de polvo en el área de molienda depende de la materia prima empleada y de su grado de humedad, así como de las características del molino.

Si el grado de humedad es elevado puede ser innecesaria la captación de polvos.

Cuando la formación de polvo es un problema, éste puede ser recogido por ciclones o filtros de mangas. En algunos casos, sin embargo, bastará regar con agua la zona de molienda. 
También se levantan grandes cantidades de polvo en las operaciones de almacenamiento, transporte y manipulación de los productos granulados o pulverulentos. Este tipo de contaminación afecta, sobre todo, al ambiente interior de la factoría e interesa vivamente al Servicio de Seguridad e Higiene en el Trabajo. Un capotado adecuado de las bandas transportadoras y aspiraciones de aire dotadas de desempolvadores, del tipo filtro de mangas principalmente, permiten reducir estas emisiones.

Las emisiones producidas por la caída de las materias primas en las operaciones de carga y descarga a lo largo del proceso de fabricación o en los parques de almacenamiento, pueden disminuirse sensiblemente limitando las alturas de caída, capotando adecuadamente el área de carga y descarga, y filtrando el aire con filtros de mangas, por ejemplo.

En el caso de que el almacenamiento de materias primas presente problemas de levantamiento de polvo, suelen humedecerse con agua llevando tensioactivos en disolución.

También se producen emisiones de polvo en la fase de preparación de la materia prima para la producción del clínker. El proceso de vía húmeda, sin embargo, produce relativamente poca contaminación, ya que se trabaja con productos granulados muy húmedos o con papillas. En el proceso de vía seca o semiseca las emisiones de polvo se producen durante la molienda y en la fase de homogeneización o mezclado. En el primer caso el desempolvado puede realizarse por medio de filtros electrostáticos, ciclones o filtros de mangas.

El foco más importante de polvo en las plantas de cemento está constituido por la unidad de producción de clínker. Esta se divide en tres partes: alimentador, horno de cocción y enfriador de clínker.

$\mathrm{Al}$ atravesar los gases calientes el horno rotativo arrastran partículas de caliza, marga y otras materias primas contenidas en el mismo. Las concentraciones de polvo en los gases de salida dependen de la velocidad y temperatura de los gases, así como del tamaño de las partículas arrastradas.

Una causa de emisión de polvo, en la fase de calcinación de la caliza por el proceso de vía húmeda, son las fugas de polvo del horno debido a pequeñas explosiones de algunos gases que se forman en el mismo, así como a las dilataciones del material. Esto explica el porqué en algunas plantas de proceso de vía húmeda se registran mayores pérdidas de polvo que en las de vía seca.

El volumen de humos a la salida del horno de clínker varía según el proceso de fabricación:

$\begin{array}{lr}\text { Horno rotativo, vía húmeda } & 3,3-4,5 \\ \text { Horno rotativo, vía seca } & 1,6-2,5 \\ \text { Horno rotativo, vía semiseca (Lepoll) } & 1,8-2,8 \\ \text { Horno vertical } & 2,0-3,5\end{array}$

Una parte más o menos importante de los polvos generados por el horno puede ser reintroducida en el proceso. 
El aire de refrigeración del clínker sirve totalmente, en los procesos de vía húmeda, o parcialmente, en los de vía seca y semiseca, como aire secundario en el horno. Ello permite reducir las emisiones de polvo. No obstante, en muchos casos, la cantidad máxima de álcalis limita este tipo de operaciones.

El reciclado de los gases de salida del horno en el proceso de vía húmeda puede hacerse de tres formas: $1 .^{\circ}$ devolviéndolo directamente al horno; $2 .^{\circ}$ recogiéndolo en un lavador de gases para mezclarlo después con la materia prima; y. $3 .^{\circ}$ insuflándolo en el horno mezclado con el carbón pulverizado, en el caso que se utilice este combustible. No obstante, este último método no es, en general, satisfactorio por las frecuentes paradas del horno debidas a obstrucciones en los mecheros de inyección de combustible.

La captación del polvo arrastrado por los gases de salida del horno del clínker se hace normalmente con captadores de alta eficacia, debido al pequeño tamaño de las partículas, que en un $55 \%$ son menores de 10 micras. Por esta razón, no es recomendable la utilización de multiciclones cuyo rendimiento es de sólo un 60 a un $87 \%$, si bien pueden combinarse con otros tipos de filtros.

Lo más corriente es que se utilicen electrofiltros, que unen a su ventaja de tener una reducida pérdida de carga, el poseer un rendimiento elevado — del orden del 96 al $97 \%$ además, su consumo de energía es relativamente bajo, calculándose que la potencia necesaria es de $0,25 \mathrm{~kW}$ para un caudal de gases de $1.000 \mathrm{~m}^{3} / \mathrm{h}$.

La depuración de los gases del horno de clínker también puede hacerse mediante filtros de mangas, si bien, en los procesos por vía seca, es necesario dotarlos de tejidos de fibra de vidrio resistentes a altas temperaturas. Su rendimiento es del orden del 99,5\%. Este tipo de filtros se encuentra más extendido en América que en Europa.

Las temperaturas de los gases, según el proceso utilizado son las que se detallan en el cuadro siguiente:

\begin{tabular}{lc}
\hline & \multicolumn{1}{c}{ c } \\
\hline Horno rotativo, vía húmeda & $120-220$ \\
Horno rotativo, vía seca & $280-350$ \\
Horno rotativo, vía semiseca (Lepol) & $80-130$ \\
Horno vertical & $50-190$ \\
\hline
\end{tabular}

Para depurar los gases procedentes de los enfriadores de clínker suelen utilizarse filtros de grava. A veces se utilizan ciclones, que, si bien tienen la ventaja de su fácil y poco costoso mantenimiento, en cambio su rendimiento es muy bajo y sufren un rápido desgaste.

El clínker debe ser almacenado en naves cerradas, si bien el cierre total de las mismas requiere la automatización de las operaciones de carga y descarga, a causa de la pérdida de visibilidad que se produce.

El polvo emitido en la molienda del clínker se elimina sin problemas en filtros de mangas, como consecuencia de que su tamaño oscila alrededor de las 2 micras.

Cuando el almacenamiento en silo se hace por transporte neumático es necesario colocar un filtro de mangas antes de que el aire sea devuelto a la atmósfera.

En cuanto a la operación de ensacado, el desempolvado del aire se efectúa generalmente con la ayuda de campanas de aspiración y filtros de mangas. 
En términos generales puede estimarse que el volumen total de gases que es preciso tratar en una planta de cemento moderna es del orden de 10 a $15 \mathrm{~m}^{3} \mathrm{~N} / \mathrm{kg}$ de clínker producido. Grosso modo, este volumen procede en un $25 \%$ del horno de cocción, en otro $25 \%$ del refrigerador de clínker y en un $50 \%$ de las instalaciones auxiliares (es decir, molienda, almacenamiento, transporte y ensacado).

En el argot de la contaminación, se denominan factores de emisión los volúmenes de cada contaminante referidos a la unidad de producción, generados de forma natural por el proceso de fabricación y emitidos a la atmósfera sin mediar ningún depurador intermedio.

Los factores de emisión son muy variables, ya que dependen del proceso elegido, del diseño de la planta, de las materias primas utilizadas, de la energía disponible, del mantenimiento de la instalación y de la operación de la misma.

La EPA americana, después de haber estudiado cuidadosamente un buen número de plantas de cemento instaladas en Estados Unidos, ha determinado los siguientes factores de emisión de polvo medios:

kg DE POLVO POR TONELADA DE CEMENTO PRODUCIDO

\begin{tabular}{lcccc}
\hline & Horno de clínker & Molinos & Total \\
\hline Proceso vía seca & 122 & 48 & 170 \\
Proceso vía húmeda & 114 & 16 & 130 \\
\hline
\end{tabular}

Los "ratios" anteriores representan una emisión equivalente al $17 \%$ de la cantidad total de cemento producido en el proceso vía seca y del $13 \%$ en el de vía húmeda.

Si se tienen en cuenta las otras instalaciones auxiliares (almacenamiento, transporte y ensacado), dichos índices podrían elevarse al 26 y $20 \%$, respectivamente.

La concentración de polvo de los gases a la salida del horno, antes de su paso por los depuradores, en un proceso de vía seca puede oscilar entre 2,5 y $28 \mathrm{~g} / \mathrm{m}^{3}$, siendo muy normales concentraciones de 11 a $22 \mathrm{~g} / \mathrm{m}^{3}$; la media se sitúa alrededor de los $14,5 \mathrm{~g} / \mathrm{m}^{3}$. En un proceso de vía humeda puede variar entre 2 y $25 \mathrm{~g} / \mathrm{m}^{3}$, con una media de 13,5 $\mathrm{g} / \mathrm{m}^{3}$.

Las mayores emisiones de polvo en el proceso de vía seca se deben fundamentalmente a los secadores. A menudo, en efecto, la molienda de la materia prima se efectúa con un secado por barrido de gases calientes (temperatura aproximada de $250^{\circ} \mathrm{C}$ ).

La colocación de filtros en cada foco emisor reduce las emisiones considerablemente. La legislación de Estados Unidos, Francia, Suiza establece para los gases procedentes de los hornos de clínker una concentración máxima de polvos de $150 \mathrm{mg} / \mathrm{m}^{3} \mathrm{~N}$, y la de Alemania reduce este nivel hasta $120 \mathrm{mg} / \mathrm{m}^{3} \mathrm{~N}$. Para los enfriadores de clínker, este último país limita el contenido en polvo de los efluentes a $75 \mathrm{mg} / \mathrm{m}^{3} \mathrm{~N}$. En la tabla que sigue pueden verse los niveles previstos en la legislación de algunos países: 
Niveles de emisión de polvos en las fábricas de cemento exigidos en la legislación extranjera

\begin{tabular}{|c|c|c|c|}
\hline & \multicolumn{3}{|c|}{$\mathbf{m g} / \mathbf{m}^{3} \mathbf{N}$} \\
\hline & Hornos & $\begin{array}{l}\text { Enfriadores } \\
\text { del clínker }\end{array}$ & Otros focos \\
\hline $\begin{array}{llllllllll}\text { Alemania Federal } & \ldots & \ldots & \ldots & \ldots & \ldots & \ldots & \ldots\end{array}$ & 120 & 75 & 75 \\
\hline Estados Unidos (en $\mathrm{g} / \mathrm{\dagger}$ de materia prima) & 150 & 50 & - \\
\hline $\begin{array}{llllllllll}\text { Francia } & \ldots & \ldots & \ldots & \ldots & \ldots & \ldots & \ldots & \ldots & \ldots\end{array}$ & 150 & 150 & 150 \\
\hline Gran Bretaña: & & & \\
\hline 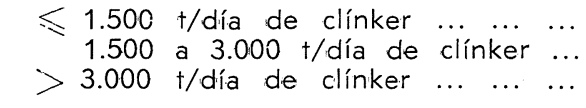 & $\begin{array}{l}460 \\
230-460 \\
230\end{array}$ & $\begin{array}{l}230 \\
230 \\
230\end{array}$ & $\begin{array}{l}230 \\
230 \\
230\end{array}$ \\
\hline Japón: & & & \\
\hline 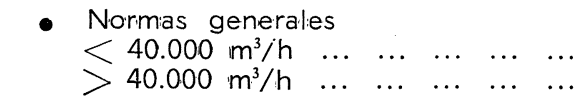 & $\begin{array}{l}400 \\
200\end{array}$ & - & - \\
\hline 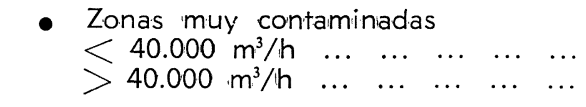 & $\begin{array}{l}200 \\
100\end{array}$ & - & - \\
\hline $\begin{array}{lllllllllll}\text { Suecia } & \ldots & \ldots & \ldots & \ldots & \ldots & \ldots & \ldots & \ldots & \ldots & \ldots\end{array}$ & $250(1)$ & - & 250 \\
\hline $\begin{array}{lllllllllll}\text { Suiza } & \ldots & \ldots & \ldots & \ldots & \ldots & \ldots & \ldots & \ldots & \ldots & \ldots\end{array}$ & $155(2)$ & 155 & 155 \\
\hline $\begin{array}{l}\text { (1) Instalaciones existentes: } 500 \mathrm{mg} / \mathrm{m}^{3} \mathrm{~N} \\
\text { (2) Instalaciones existentes: } 230 \mathrm{mg} / \mathrm{m}^{3} \mathrm{~N}\end{array}$ & & & \\
\hline
\end{tabular}

El esfuerzo desplegado por la industria cementera de muchos países europeos para limitar las emisiones de polvo a la atmósfera ha sido notable. Bastaría con citar el caso francés en que las emisiones de polvo se han reducido de 240.000 t en 1950 a 100.000 t en 1975, mientras la producción de cemento ha aumentado desde los 7 millones de toneladas de 1950 hasta los 34,4 millones de toneladas en 1975. Es decir que, mientras la producción se ha incrementado en 25 años en un $390 \%$, las emisiones de polvo se han reducido en un $58 \%$ :

\begin{tabular}{ccccc}
\hline Año & $\begin{array}{c}\text { Producción } \\
\text { de cemento } \\
\text { millones t }\end{array}$ & $\begin{array}{c}\text { Emisión } \\
\text { de polvo } \\
\text { t }\end{array}$ & $\begin{array}{c}\text { Polvo emitido } \\
\text { en kg/t cemento }\end{array}$ & $\begin{array}{c}\text { Polvo emitido } \\
\text { en \% producción } \\
\text { de cemento }\end{array}$ \\
\hline 1950 & 7,0 & 240.000 & 35 & 3,5 \\
1957 & 11,5 & 170.000 & 15 & 1,5 \\
1967 & 24,0 & 120.000 & 5 & 0,5 \\
1975 & 34,4 & 100.000 & 2,9 & 0,29 \\
\hline
\end{tabular}

El porcentaje de polvo emitido sobre la producción de cemento que en 1950 era del 3,5 \% ha pasado al 0,29 \% en 1975. Las plantas de cemento modernas, con un rendimiento de desempolvado del $99,7 \%$, arrojan a la atmósfera polvo en una cuantía que puede oscilar entre el 0,03 y el $0,05 \%$ de la producción de cemento.

Ya que nos hemos referido a la contaminación producida por la industria del cemento en Francia, conviene citar que, en 1973, el $71 \%$ de la producción de cemento se obtenía por el proceso de vía seca, existiendo una acción concertada del Gobierno con las empresas para incrementar esta participación a fin de situarla en el $85 \%$ en el año 1980. 
Asimismo, conviene señalar que la legislación vigente en Francia establece unos niveles de emisión de polvo de $150 \mathrm{mg} / \mathrm{m}^{3} \mathrm{~N}$ en todos los focos. El cumplimiento de esta exigencia supone un aumento del coste de producción del cemento de un 3,5\%.

En Inglaterra, también ha sido notable la reducción de las emisiones de polvo por parte de las fábricas de cemento. En el período que va entre los años 1958 y 1974 (16 años), dichas emisiones se han reducido en un $84 \%$, pese a que la producción de cemento se ha incrementando durante estos 16 años en un $60 \%$ :

\begin{tabular}{ccccc}
\hline Año & $\begin{array}{c}\text { Producción } \\
\text { de cemento } \\
\text { millones t }\end{array}$ & $\begin{array}{c}\text { Emisión } \\
\text { de polvo } \\
\mathbf{t}\end{array}$ & $\begin{array}{c}\text { Polvo emitido } \\
\text { en } \mathbf{k g} / \mathbf{t} \text { cemento }\end{array}$ & $\begin{array}{c}\text { Polvo emitido } \\
\text { en \% producción } \\
\text { de cemento }\end{array}$ \\
\hline 1958 & 10,0 & 160.000 & 16,0 & 1,6 \\
1972 & 16,0 & 37.000 & 2.3 & 0,23 \\
1974 & 16,1 & 25.000 & 1,5 & 0,15 \\
\hline
\end{tabular}

Mientras en 1958 se emitían $16 \mathrm{~kg}$ por tonelada de cemento, en 1974 se emitieron sólo $1,5 \mathrm{~kg}$.

Este ha sido el resultado de reducir los niveles de emisión desde los $1.150 \mathrm{mg} / \mathrm{m}^{3}$ exigidos en el año 1958 a los 230 a $460 \mathrm{mg} / \mathrm{m}^{3}$, según el tamaño de la planta, en 1974.

En el período 1958-1968, la industria británica del cemento ha invertido 6 millones de libras esterlinas en desempolvadores, frente a los 150 millones invertidos por el conjunto de la industria en la lucha contra la contaminación atmosférica. Los gastos de operación a lo largo de estos diez años han sido de 6 millones de libras en la industria del cemento y de 324 millones en el sector industrial en su conjunto. En el último año del período considerado, los gastos de operación de los filtros han supuesto un $16 \%$ de la inversión acumulada en las instalaciones de depuración, mientras que para el conjunto de la industria dicho índice se situó en el $26 \%$ :

Coste de la lucha contra la contaminación atmosférica en Inglaterra en el periodo 1958-1968

(en $10^{6}$ Libras Esterlinas)

\begin{tabular}{ccccc}
\hline & Inversión & $\begin{array}{c}\text { Investigación } \\
\text { y desarrollo }\end{array}$ & $\begin{array}{c}\text { Gastos de } \\
\text { funcionamiento } \\
\text { en los 10 años }\end{array}$ & $\begin{array}{c}\text { Gastos de } \\
\text { funcionamiento } \\
\text { en el último año }\end{array}$ \\
\hline Industria del cemento & 6,2 & 0,3 & 6,4 & 1,0 \\
Sector industrial & 150,3 & 4,9 & 324,4 & 39,0 \\
\hline
\end{tabular}

De los 98 hornos de cemento en funcionamiento en Inglaterra en el año 1974, 94 estaban equipados con electrofiltros y 4 con ciclones.

En Estados Unidos, el rendimiento medio de los filtros instalados en las fábricas de cemento construidas con anterioridad a 1960 era de un $95 \%$, y de un $99 \%$ para los de las fábricas construidas en el período 1960-67. Actualmente el redimiento puede ser del orden del $99,7 \%$. 
El impacto de la lucha contra la contaminación de la atmósfera en Estados Unidos se ha reflejado en un incremento del precio de costo del cemento de un 2,7 a un 3,3\%.

En Suecia, los gases procedentes de los hornos del clínker son depurados en filtros electrostáticos con 1, 2 ó 3 secciones en paralelo. Los gases una vez depurados tienen un contenido en polvo de $100 \mathrm{mg} / \mathrm{m}^{3} \mathrm{~N}$ e incluso de $75 \mathrm{mg} / \mathrm{m}^{3} \mathrm{~N}$. Las instalaciones auxiliares utilizan, generalmente, ciclones, filtros de mangas o separadores húmedos, según los casos, y también filtros electrostáticos para las emisiones del molino del clínker.

Las instalaciones de desempolvado vienen a representar entre un 7 y un $10 \%$ de la inversión total de la planta de cemento, siendo el porcentaje mayor el usual para adaptarse a los niveles de emisión exigidos por las legislaciones más recientes en muchos países del mundo occidental.

En una planta moderna las inversiones en medidas correctoras de la contaminación de la atmósfera se distribuyen de la siguiente forma:

\begin{tabular}{|c|c|}
\hline & $\%$ \\
\hline \multirow{3}{*}{ 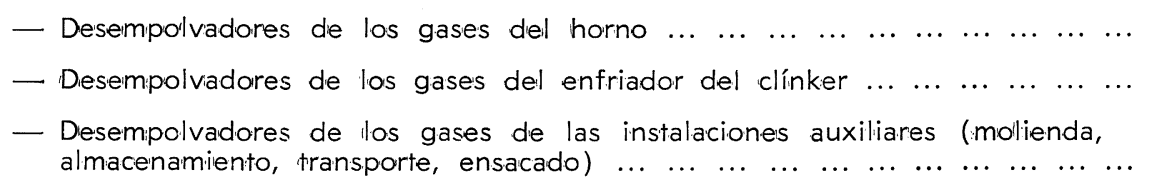 } & 38 \\
\hline & 14 \\
\hline & 48 \\
\hline $\begin{array}{lllll}\text { TOTAL } & \ldots & \ldots & \ldots & \ldots\end{array}$ & 100 \\
\hline
\end{tabular}

Mientras en las plantas modernas la inversión en las instalaciones auxiliares es algo menos de la inversión total en instalaciones de depuración, en las plantas antiguas su participación es bastante reducida, ya que apenas representa el $23 \%$.

Para conocer el alcance real de los porcentajes anteriores, debe aclararse que el monto de la inversión en equipos de desempolvado incluye el filtro propiamente dicho, los ventiladores, los conductos, la chimenea, así como su montaje y obra civil.

Los gastos de mantenimiento de las instalaciones depuradoras (tales como reposición de mangas filtrantes, etc.) vienen a representar entre el 1,5 y el $3,5 \%$ del costo de dichas instalaciones.

Los gastos de explotación, por su parte (que incluyen el agua, electricidad y mano de obra, pero no incluyen los gastos de amortización), vienen a representar entre el 4,5 y $7,5 \%$ de la inversión en equipos de desempolvado.

En conjunto, pues, los gastos de mantenimiento y explotación de los filtros en una instalación por vía seca ascienden al 6 y $11 \%$ del costo de los mismos. A estos gastos habría que añadir los de amortización.

Aparte de la emisión de polvos, las fábricas de cemento también despiden otros contaminantes en mucha menor cuantía, desde luego, procedentes de la combustión de los combustibles empleados en el horno. Los gases emitidos son los clásicos de la combustión, es decir, óxidos de nitrógeno y anhídrido sulfuroso, fundamentalmente.

Los óxidos de nitrógeno se forman como consecuencia de las altas temperaturas a que trabajan los hornos de clínker. Según la EPA de Estados Unidos, el factor de emisión de los óxidos de nitrógeno es de 1,3 kg por tonelada de cemento producido. 
La cantidad de anhídrido sulfuroso que se emite a la atmósfera es pequeña y depende del contenido de azufre en las materias primas y, sobre todo, en el combustible utilizado. Dicho azufre es retenido y fijado por el clínker entre un 84 y un $90 \%$, en forma de sulfatos alcalinos y sulfato cálcico, así como en los polvos de electrofiltros y colectores intermedios.

La fijación del azufre en el clínker no sólo es beneficiosa sino necesaria para el proceso de fabricación, para el rendimiento energético y para la calidad del cemento resultante. Tanto es así que cuando el combustible no tiene el azufre necesario, se hace preciso incorporar compuestos de azufre a los crudos.

Como consecuencia de la retención y fijación del azufre del combustible empleado, la contaminación atmosférica por emisión de dióxido de azufre en fábricas de cemento es muy reducida cuando se utilizan los combustibles convencionales. Por ello, por Orden del Ministerio de Industria de 28 de julio de 1976, la fabricación de cemento queda eximida del cumplimiento de lo dispuesto en el Decreto 2.204 de 23 de agosto de 1975, según el cual, en las instalaciones industriales que se encuentren situadas a menos de $2 \mathrm{~km}$ de un núcleo urbano superior a los 10.000 habitantes, no podrán consumir combustibles que contengan más del $3 \%$ de azufre.

Cabe indicar aquí, que en España son muy pocas las cementeras que consumen carbón. En general, se consume fuel-oil, el cual, en 1973, representaba el $81 \%$ del tonelaje de combustible utilizado en esta industria.

Actualmente el fuel-oil consumido en España tiene el $3 \%$ largo de azufre. El nuevo tipo de fuel-oil, denominado pesado n. ${ }^{\circ} 2$ contendrá el $3,6 \%$. Este empeoramiento de la calidad de este combustible se compensa, con la aparición en el mercado de fuel-oil pesado n. ${ }^{\circ}$, con un contenido en azufre del $2,5 \%$.

El consumo de combustible varía según el rendimiento térmico del horno, la composición de las materias primas, el proceso de fabricación y otros muchos factores que intervienen en la operación. Según el proceso (vía seca, semiseca o húmeda), el consumo varía de 80 a $160 \mathrm{~kg}$ de fuel-oil por tonelada de clínker producido.

Por todo lo anterior, el perjuicio producido por el $\mathrm{SO}_{2}$ emitido por las fábricas de cemənto se considera generalmente como despreciable.

Además de los contaminantes citados, en el proceso de vía húmeda pueden producirse malos olores según las materias primas utilizadas (conchas de moluscos y algunos tipos de arcilla), debido al desprendimiento de ácido sulfhídrico.

\section{Encuesta sobre la contaminación de la atmósfera por la industria del cemento en España}

Al objeto de conocer la situación real del problema de la contaminación atmosférica en nuestro país, tanto a escala sectorial como territorial, la Subdirección General del Medio Ambiente Industrial ha realizado una encuesta que afecta a una muestra de 2.700 establecimientos industriales y se refiere a datos del año 1973. En la actualidad se está llevando a cabo una nueva encuesta referida al año 1975 sobre una muestra de más de 5.000 industrias.

Este inventario de focos industriales potencialmente contaminadores de la atmósfera responde a lo previsto en la disposición final primera del Decreto 833 de 6 de febrero de 1975. Pese a la obligatoriedad de contestación del cuestionario remitido al efecto, sólo se han recibido un $31 \%$ de contestaciones. 
Por lo que se refiere al sector del cemento se han recibido respuestas de 45 establecimientos que cubren un $75,8 \%$ de la producción, estimada en 24,5 millones de toneladas en el año 1973.

Al objeto de conocer mejor el comportamiento de las plantas de cemento en función de su tamaño, se han clasificado en tres grupos:

Número de cuestionarios recibidos

\begin{tabular}{lc}
\hline Pequeñas (hasta 200.000 t/año) & 15 \\
Medianas (entre 200.000 y 600.000 t/año) & 16 \\
Grandes (más de 600.000 t/año) & 14 \\
\hline
\end{tabular}

Se han recibido 15 cuestionarios debidamente cumplimentados por parte de establecimientos pequeños, 16 de establecimientos medianos y 14 de establecimientos grandes.

Para cada uno de estos grupos se ha investigado la antigüedad de las instalaciones, el tipo de proceso y el sistema de depuración utilizado, al objeto de explicar las diferencias que se ofrecen en dos variables fundamentales analizadas; a saber: la emisión de polvos y la inversión realizada en equipos de depuración.

\begin{tabular}{ccccc}
\hline \multicolumn{1}{c}{ ANTIGÜEDAD } \\
\hline $\begin{array}{c}\text { Tamaño de las } \\
\text { instalaciones }\end{array}$ & Anterior a 1960 & Entre 1960 y 1970 & Posterior a 1970 & Total \\
\hline Pequeñas & 10 & 4 & 1 & 15 \\
Medianas & 7 & 9 & 0 & 16 \\
Grandes & 4 & 7 & 3 & 14 \\
\hline T O T A L & 21 & 20 & 4 & 45 \\
\hline
\end{tabular}

Se ha comprobado que de las 45 instalaciones 21 son anteriores al año 1960, 20 se han construido entre los años 1960 y 1970, y 4 son posteriores a 1970. Cabe destacar que, como era de esperar, las industrias pequeñas son las más antiguas y las nuevas plantas son generalmente grandes:

\begin{tabular}{lc}
\hline Proceso de fabricación & Número de instalaciones \\
\hline Vía seca & 30 \\
Vía húmeda & 7 \\
Mixto & 5 \\
Sólo molienda de clínker & 3 \\
\hline
\end{tabular}


De las 45 plantas analizadas, 30 utilizan el procedimiento de vía seca, 7 el de vía húmeda, 5 un sistema mixto y 3 se dedican exclusivamente a la molienda de clínker.

En España como en casi todos los países del mundo occidental los procesos de vía húmeda - que requieren menos inversión y ofrecen una explotación más cómoda- han sido progresivamente abandonados en beneficio de la vía seca, que consume un $33 \%$ menos de energía, es decir unas 945 thermias por tonelada de clínker.

Por considerar que los datos de emisiones de polvo facilitados por los industriales no eran demasiado fiables, se han determinado por la vía teórica, en la forma en que se realiza en otros países al elaborar sus propios inventarios de emisiones de contaminantes.

La metodología utilizada ha sido la siguiente: en primer lugar se ha determinado el volumen total de humos emitidos anualmente; para ello, se han tenido en cuenta los caudales horarios dados por los empresarios $\left(\mathrm{m}^{3} \mathrm{~N} / \mathrm{h}\right)$ y se han calculado las horas de funcionamiento, deduciendo de las horas teóricas las horas de paro de cada instalación, de acuerdo con las estadísticas de la Subdirección General de Industrias de la Construcción. En segundo lugar, se han estimado las toneladas de polvo emitidas por cada planta antes del desempolvado; se han utilizado para ello los factores de emisión de la EPA que dan los $\mathrm{kg}$ de polvo/t de cemento para cada fase del proceso de fabricación. En tercer lugar, se han estimado los rendimientos de depuración de cada filtro en función de su antigüedad: hasta el año 1960, se ha supuesto un rendimiento del $90 \%$, entre 1960 y 1970, del $94 \%$, y posteriores al año 1970, del $96 \%$. La aplicación de estos rendimientos a la depuración de las emisiones de polvo calculadas anteriormente, dan un volumen de emisiones teórico para cada planta, que dividido por la producción realmente obtenida en el año por dicha planta, da el índice de emisión en $\mathrm{kg}$ de polvo por tonelada de cemento.

Los resultados obtenidos han sido los siguientes:

\begin{tabular}{|c|c|c|}
\hline & Emisión de & $\begin{array}{l}\text { polvo } \mathrm{kg} / \mathrm{t} \text { de cemento } \\
\text { (mediana) }\end{array}$ \\
\hline Tamaño de las instalaciones & Estimación & Encuesta \\
\hline $\begin{array}{llllllllllll}\text { Pequeñas } & \ldots & \ldots & \ldots & \ldots & \ldots & \ldots & \ldots & \ldots & \ldots & \ldots & \ldots\end{array}$ & 15,81 & 2,41 \\
\hline $\begin{array}{llllllllllll}\text { Medianas } & \ldots & \ldots & \ldots & \ldots & \ldots & \ldots & \ldots & \ldots & \ldots & \ldots & \ldots\end{array}$ & 13,79 & 0,95 \\
\hline $\begin{array}{lllllllllllll}\text { Grandes } & \ldots & \ldots & \ldots & \ldots & \ldots & \ldots & \ldots & \ldots & \ldots & \ldots & \ldots & \ldots\end{array}$ & 10,20 & $0 ; 90$ \\
\hline $\begin{array}{lllllllllll}\text { Total muestra } & \ldots & \ldots & \ldots & \ldots & \ldots & \ldots & \ldots & \ldots & \ldots & \ldots\end{array}$ & 13,70 & 1,08 \\
\hline
\end{tabular}

\begin{tabular}{|c|c|c|}
\hline & Emisión de & $\begin{array}{l}\text { polvo } \mathrm{kg} / \mathrm{t} \text { de cemento } \\
\text { (mediana) }\end{array}$ \\
\hline Proceso de fabricación & Estimación & Encuesta \\
\hline $\begin{array}{llllllllllllll}\text { Vía seca } & \ldots & \ldots & \ldots & \ldots & \ldots & \ldots & \ldots & \ldots & \ldots & \ldots & \ldots & \ldots\end{array}$ & 14,40 & 0,95 \\
\hline $\begin{array}{lllllllllll}\text { Vía húmeda } & \ldots & \ldots & \ldots & \ldots & \ldots & \ldots & \ldots & \ldots & \ldots & \ldots\end{array}$ & 13,00 & 1,56 \\
\hline $\begin{array}{lllllllllllll}\text { Mixto } & \ldots & \ldots & \ldots & \ldots & \ldots & \ldots & \ldots & \ldots & \ldots & \ldots & \ldots & \ldots\end{array}$ & 10,60 & 1,35 \\
\hline $\begin{array}{llllllllllll}\text { Total muestra } & \ldots & \ldots & \ldots & \ldots & \ldots & \ldots & \ldots & \ldots & \ldots & \ldots & \ldots\end{array}$ & 13,70 & 1,08 \\
\hline
\end{tabular}

El análisis de estos resultados pone de manifiesto, en primer lugar, la escasa bondad de la información obtenida de los cuestionarios, ya que, según los empresarios, la industria cementera española sería mucho más limpia que la inglesa. En efecto, mientras la indus- 
tria británica emitió, en 1974, 1,5 kg de polvo por tonelada de cemento, la española, en 1973, habría emitido 1,08 kg; conclusión evidentemente absurda, sobre todo, si se tiene en cuenta que mientras en España el nivel de emisión de polvos por las fábricas de cemento admitido hasta el 1 de julio de 1976 era de $800 \mathrm{mg} / \mathrm{m}^{3} \mathrm{~N}$, en el Reino Unido era de $230 \mathrm{mg} / \mathrm{m}^{3} \mathrm{~N}$ y en Francia de $150 \mathrm{mg} / \mathrm{m}^{3} \mathrm{~N}$.

Por el contrario, el nivel estimado de $13,7 \mathrm{~kg}$ parece bastante ajustado a la realidad, ya que era el existente en Francia hacia el año 1958 y en Inglatera hacia el año 1959. Y no hay que olvidar que la legislación británica en materia de lucha contra la contaminación atmosférica data de 1956, la francesa de 1961 y la española de 1972. Resulta curioso observar que los 16 años que median entre la promulgación de la Clean Air Act y la Ley de Protección del Ambiente Atmosférico concuerdan bastante bien con los 14 años que separan el nivel de 13,7 kg conseguido en España en 1973 con relación a la fecha en que fue alcanzado en el Reino Unido (año 1959).

Otra información de interés, resultante de la encuesta, es la concentración de polvo en $\mathrm{mg} / \mathrm{m}^{3} \mathrm{~N}$, que como media emite cada planta cementera. Los resultados son los siguientes:

\begin{tabular}{ll}
\hline Pequeñas & 2.420 \\
Medianas & 1.985 \\
Grandes & 2.970 \\
\hline Total muestra & 2.500 \\
\hline
\end{tabular}

Estos resultados son muy extraños, ya que no tiene sentido que las industrias grandes, que son las más modernas, sean precisamente las que registran unos niveles de emisión más altos. También resulta inexplicable que las industrias de tamaño medio sean las más limpias.

Resulta, asimismo, anómalo un nivel medio tan elevado de $2.500 \mathrm{mg} / \mathrm{m}^{3} \mathrm{~N}$. Sirva de comparación la legislación inglesa que en el año 1958 permitía un nivel de emisión de polvos de $1.150 \mathrm{mg} / \mathrm{m}^{3} \mathrm{~N}$. Esta anomalía puede deberse a haber infraestimado el volumen de gases, en tanto que la cantidad de polvos se ha estimado más correctamente. Es probable, en efecto, que el volumen total de gases sólo considere los del horno y molienda de clínker, habiendo omitido los del enfriador de clínker y operaciones auxiliares, lo que equivale a la omisión de un volumen del mismo orden que el considerado de acuerdo con el desglose que hemos dado en otro lugar. Ello supondría haber supervalorado la emisión en el doble.

Por otra parte, habría que considerar un incremento de un $10 \%$ por paradas, ya que las que se han tenido en cuenta para calcular el volumen de gases resultan infraestimadas. De acuerdo con estas consideraciones, el nivel de emisión resultante debiera ser aproximadamente de $1.150 \mathrm{mg} / \mathrm{m}^{3} \mathrm{~N}$, concordante con el nivel admitido en Inglaterra en el año 1958.

Otra magnitud investigada ha sido la inversión. A tal fin, se ha calculado para cada establecimiento el tanto por ciento que la inversión en equipos de depuración representa sobre la inversión total en instalaciones productivas, obteniéndose los siguientes resultados globales: 


\begin{tabular}{lc}
\hline Tamaño de las instalaciones & $\begin{array}{c}\text { de las inversiones en equipos de depuración } \\
\text { sobre !a inversión total (mediana) }\end{array}$ \\
\hline Pequeñas & 7,00 \\
Medianas & 7,79 \\
Grandes & 9,25 \\
\hline
\end{tabular}

Tampoco estos indicadores, deducidos de la información facilitada por las empresas, es correcta, ya que en los países cuyas industrias se ajustan a una legislación bastante estricta, este indicador varía entre 7 y $10 \%$, como ya hemos indicado. Es probable que esta anomalía se deba a que los filtros han sido valorados en pesetas no comparables con las pesetas del año en que se construyeron las instalaciones productivas. Es posible, sin embargo, que alguna de las plantas grandes estén en línea con las más modernas europeas, en cuyo caso el $9 \%$ de inversión en equipos de depuración sería adecuado a las mismas.

Los 45 establecimientos investigados tienen instalados 113 electrofiltros y 246 filtros de mangas; el resto son multiciclones en número no determinado. Como media, resulta que cada fábrica de cemento tiene 2,5 electrofiltros y 5,5 filtros de mangas.

Para terminar con el análisis de los resultados de la encuesta, es de interés conocer la participación que la industria cementera tiene en el problema global de contaminación de polvos producidos por el conjunto de la industria.

\begin{tabular}{|c|c|c|c|}
\hline & \multicolumn{3}{|c|}{ Polvos emitidos por la industria en 1973 en t/año } \\
\hline & \multicolumn{2}{|c|}{$\begin{array}{l}\text { Establecimientos que han } \\
\text { contestado al cuestionario }\end{array}$} & \multirow{2}{*}{$\begin{array}{l}\text { Estimación para el } \\
\text { conjunto nacional }\end{array}$} \\
\hline & Estimación & Encuesta & \\
\hline Industria del cemento & 224.652 & 22.915 & 304.872 \\
\hline Sector industrial & 401.473 & 92.660 & 1.283 .519 \\
\hline$\%$ industria del cemento sobre sector industrial & 56 & 25 & 24 \\
\hline
\end{tabular}

La industria del cemento vierte a la atmósfera unas 305.000 t/año de partículas sólidas, que equivalen a la cuarta parte de la emisión total de polvos por la industria. Este hecho es digno de ser resaltado para que todos los industriales tomen conciencia de la importancia del problema de este sector.

Quisiera añadir algo más respecto a la encuesta: si bien los datos facilitados son totalmente erróneos, las conclusiones son altamente ilustrativas sobre la situación real del sector. Por otra parte, el estudio de las contestaciones recibidas hacen suponer que el industrial no conoce con exactitud el impacto ambiental de su planta y, a este respecto cabe señalar el principio comúnmente reconocido de que sólo es posible atacar un problema cuando se conoce su existencia y su verdadera magnitud.

\section{Aspectos de la legislación anticontaminación que interesan a la industria del cemento}

La industria del cemento ha sido en casi todos los países una de las primeras en merecer la atención de los legisladores en materia de protección del medio ambiente, por lo menos en el siglo actual. En el siglo XIX las preocupaciones se centraban principalmente 
en las emisiones de humos producidas indiscriminadamente por cualquier actividad que quemara masivamente carbón en hogares de diseño todavía elemental, si bien fue la extensión del proceso Leblanc de obtención de carbonato de sosa lo que dió origen a la primera legislación seria en materia de contaminación atmósférica. Me refiero a la conocida Alkali Act promulgada en Inglaterra en 1863.

Cuando en nuestro país apenas empezaba a nacer el concepto de contaminación atmósférica, la intensidad de las molestias producidas por las plantas cementeras, medida por la frecuencia de las protestas de agricultores e individuos afincados en pequeñas comunidades, generalmente de carácter rural, impulsaron al Ministerio de Industria a interesar del Gobierno la promulgación en 7 de noviembre de 1968 de un Decreto en el que se adoptaban medidas para evitar la contaminación atmósférica producida por partículas sólidas en suspensión en los gases vertidos al exterior por fábricas de cemento. Piénsese cuán vanguardista era tal disposición, cuando fue precisamente en octubre de dicho año en que una prolongada inversión de temperatura en Bilbao, unida a una situación de vientos en calma, provocó una situación de emergencia que sólo fue superada por la del mismo mes de un año más tarde. Aquí empezó la toma de conciencia del problema de la contaminación atmosférica en España.

Es cierto que ya existía desde el año 1961 el Reglamento de Actividades Molestas, Insalubres, Nocivas y Peligrosas, pero dicho Reglamento - totalmente destecnificado- se limitaba a cubrir los aspectos puramente formalistas del problema. Sin un respaldo técnico y sin un cuerpo de inspectores bien instruido, el Reglamento no pudo aportar soluciones válidas al problema de la contaminación ambiental.

El Decreto del año 1968 establecía que todas las instalaciones de fabricación o ensilado de cemento, y de molienda de clínker, existentes o futuras, debían disponer de desempolvadores a fin de evitar concentraciones de polvo en los efluentes, superiores a los 800 $\mathrm{mg} / \mathrm{m}^{3} \mathrm{~N}$ en todas las operaciones que han de realizarse desde la recepción de las materias primas hasta la expedición del producto terminado. En ningún caso, era permisible rebasar una emisión de $50 \mathrm{~kg} / \mathrm{h}$ de polvo por cada chimenea o conducto en comunicación con la atmósfera.

La Ley de Protección del Ambiente Atmosférico, promulgada en 22 de diciembre de 1972, expresó la voluntad del Gobierno, ratificada por las Cortes, de atacar seriamente el problema de la contaminación atmosférica en todas sus manifestaciones y en todos sus orígenes. En cierto modo, dicha Ley sirvió para mejorar la imagen de la industria del cemento, al diluirla entre otras muchas actividades incluidas en la Ley pero mantenidas en el anonimato.

El Decreto 833 de 6 de febrero de 1975, que constituye uno de los Reglamentos de la Ley -el relativo a la industria-, (los otros idos son el ya publicado de los vehículos automóviles y el de las calefacciones domésticas, actualmente en preparación), vino a aclarar muchas ideas pero dejó muchos cabos sueltos y profundas lagunas. Por otro lado, dejó translucir dos graves defectos: la imposición de unos niveles de emisión insuficientemente estudiados por falta total de experiencia y por escasez de la necesaria información sobre los niveles exigidos en otros países. El otro defecto fue la impracticabilidad de los plazos impuestos para la adaptación de las instalaciones existentes a los niveles exigidos en la disposición.

Es preciso explicar estas deficiencias. Veamos en primer lugar lo que he querido significar con falta de experiencia y cuales son las implicaciones que de ello se derivan. En casi todos los países industrializados la política de protección del medio ambiente ha ido madurando progresivamente. Antes del dictado de una Ley-marco, han precedido largos años de estudios preparativos e investigaciones. Se han realizado muchas mediciones en el ambiente exterior y en los focos de emisión. Todo ello ha servido de base para el dictado de una legislación, rodada, en cierto modo, antes de su promulgación. Además. 
cuando la Ley ha entrado en vigor, existía ya el equipo humano necesario debidamente adiestrado. Todos estos países, indecisos ante el estado actual de la tecnología y sus previsibles avances en el futuro, prefirieron en una primera fase, secundar la práctica británica de exigir en cada caso particular "los mejores medios practicables disponibles", antes que establecer unos niveles de emisión exigibles con carácter general. Si bien la práctica inglesa implica el conocimiento implícito de unos niveles de emisión propios de cada proceso tecnológico, su no reconocimiento oficial ha impedido durante muchos años que la experiencia adquirida tuviera una amplia difusión que sirviera de pauta a otros países, como España. Nuestro país, pues, ha salido a la palestra con unos niveles de emisión que en muchos casos no han podido tener en cuenta la realidad industrial española. La solución inglesa tampoco hubiera contribuido a arreglar las cosas, ya que, la Administración española, falta de personal, tampoco hubiera podido adquirir esta experiencia a corto plazo y, por otra parte, las sociedades de ingeniería no hubieran sabido por cual tecnología de depuración o de proceso debían decidirse.

Para paliar estas deficiencias, se acaba de elaborar una propuesta de revisión de niveles de emisión, en base a las sugerencias recibidas de industriales y sociedades de ingeniería españolas, de conocidos expertos internacionales, así como de una más exhaustiva información extranjera, procedente de países inclinados a oponer el pragmático sistema inglés el más científico y objetivo sistema de los niveles de emisión de aplicación general.

A continuación se exponen los niveles propuestos para la industria del cemento, en comparación con los actualmente vigentes. Les invito a que los estudien Vids. y los comenten; sin embargo, es importante señalar que estos niveles no pueden enjuiciarse en forma separada de los plazos que se establezcan para adecuar a los mismos las instalaciones existentes:

Niveles de emisión de polvos por la industria del cemento en la legislación española

\begin{tabular}{|c|c|c|c|c|c|c|c|}
\hline & & \multicolumn{6}{|c|}{$\mathbf{m g} / \mathbf{m}^{3} \mathbf{N}$} \\
\hline & & \multicolumn{2}{|c|}{$\begin{array}{l}\text { Instalaciones } \\
\text { existentes }\end{array}$} & \multicolumn{2}{|c|}{$\begin{array}{l}\text { Instalaciones } \\
\text { nuevas }\end{array}$} & \multicolumn{2}{|c|}{$\begin{array}{l}\text { Previsión } \\
1980\end{array}$} \\
\hline & & (1) & (2) & (1) & (2) & (1) & (2) \\
\hline \multicolumn{8}{|c|}{ Hornos y molinos de crudo: } \\
\hline & $\leqslant 1.500 \mathrm{t} / \mathrm{d}$ ía de clínker & 400 & 400 & 250 & 200 & 150 & 150 \\
\hline & $>1.500$ t/día de clínker & 400 & 300 & 250 & 170 & 150 & 120 \\
\hline & Enfriadores de clínker $\ldots \ldots \ldots$ & 170 & 200 & 100 & 120 & 50 & 80 \\
\hline & $\begin{array}{l}\text { Machacadoras, molinos de } \\
\text { cemento, ensacadoras, } \\
\text { transportes, silos y otros } \\
\text { focos contaminantes ... ... }\end{array}$ & 300 & 300 & 250 & 170 & 150 & 120 \\
\hline $\begin{array}{l}\text { (1) } \\
\text { (2) }\end{array}$ & $\begin{array}{l}\text { Anexo IV del Decreto } 833 \text { de } 6 \text { de febrero } \\
\text { Propuesta de nuevos niveles. }\end{array}$ & de 1975. & & & & & \\
\hline
\end{tabular}

Los plazos establecidos en el Decreto 833 de 6 de febrero de 1975, son no ya exigentes sino absolutamente descabellados, debido en parte al enorme retraso con que apareció dicha disposición que según la disposición final primera de la Ley de Protección del Ambiente Atmosférico, debiera haber sido promulgada antes del 27 de diciembre de 1973. De esta forma, la fecha tope de adaptación del 1 de julio de 1976, equivalía a la concesión de un plazo de dos años y medio, plazo totalmente irrealista si se tienen en cuenta dos factores: primero, la escasa capacidad de respuesta de las sociedades de ingeniería y empresas fabricantes de bienes de equipo anticontaminación ante una avalancha desmedida de pedidos; y segundo, la imposibilidad de asimilar la economía las elevadas inversiones en instalaciones improductivas y, por tanto, incapaces de autofinanciarse. 
Realizados diversos estudios sobre la incidencia económica de la política medioambiental, se desprende que una hipótesis realista para la adaptación a unos niveles de emisión similares a los que rigen en el extranjero, sería eliminar un $30 \%$ de la emisión de contaminantes por las industrias existentes cada cuatro años, lo que traería consigo la total adaptación a dichos niveles en un plazo de unos 12 años. Esta adaptación, sin embargo, conviene hacerla en forma escalonada y de acuerdo con un programa bien concebido, basado sobre una escala de prioridades -o mejor dicho de urgencias-, modulada en función de la problemática económica de cada caso concreto.

En definitiva, la propuesta de modificación de plazos se basaría en las siguientes premisas:

1. ${ }^{a} \quad$ Las industrias existentes a la entrada en vigor de la nueva disposición se adaptarían a los niveles de la primera columna en 31 de diciembre de 1980.

Se considerarán como existentes aquellas industrias autorizadas antes de la entrada en vigor de la nueva disposición, aún cuando no se hubiese realizado su puesta en marcha.

2. ${ }^{a} \quad$ Las industrias que se hubiese demostrado de forma fehaciente que producen daños y perjuicios notables a la comunidad o a parte interesada deberían reducir el plazo señalado con carácter general lo más posible y, en todo caso, debieran haber corregido sus instalaciones antes del 1 de enero de 1979.

3. $\quad$ La forma y plazos de adaptación a los niveles de emisión exigibles a las industrias serían determinados en cada caso particular por el Ministerio de Industria, respetando la fecha tope antes citada.

4. ${ }^{a} \quad$ Las industrias existentes en 31 de diciembre de 1983 se adaptarían a los niveles de la segunda columna, es decir, los previstos para las nuevas industrias.

5. ${ }^{a} \quad$ Las industrias existentes en 31 de diciembre de 1986 se adaptarían a los niveles de la tercera columna, o sea, los indicados como previsión para 1980.

6. Para las nuevas instalaciones serían de aplicación los niveles de emisión señalados en la columna dos.

Serán consideradas como industrias nuevas aquellas cuyos proyectos sean presentados o autorizados con fecha posterior a la entrada en vigor de la nueva disposición.

7. ${ }^{a} \quad$ Todas las industrias que se pusieran en marcha con posterioridad al 31 de diciembre de 1979 deberían satisfacer los niveles de emisión de la columna tres.

Aparte de la necesidad de revisión de los niveles de emisión y de los plazos, hay un punto que afecta muy directamente a la industria del cemento: el del autocontrol de la contaminación por ella producida. A este respecto, ante las inquietudes manifestadas por algunos empresarios acerca de la improcedencia de vigilar la concentración del $\mathrm{SO}_{2}$ en el entorno de las cementeras, creo conveniente clarificar que el dictado del Decreto 1.773 de 7 de junio de 1976 y Orden del Ministerio de Industria de 28 de julio de 1976 implican la modificación automática del artículo 73 del Decreto 833 de 6 de febrero de 1975, en el sentido de que las fábricas de cemento queden exentas de la obligatoriedad de medir la concentración de $\mathrm{SO}_{2}$ en el medio ambiente, toda vez que dichas disposiciones reconocen oficialmente - con el respaldo científico del Instituto Eduardo Torroja- de que la contaminación atmosférica por emisión de dióxido de azufre en fábricas de cemento es muy reducida cuando se utilizan combustibles convencionales. 
Sin embargo, dado el gran número de denuncias presentadas contra algunas fábricas de cemento, debido a las molestias producidas por emisión de polvo, no resulta posible ni parece prudente eximir a tales industrias de la obligatoriedad de vigilar la concentración de partículas sólidas en suspensión y sedimentables en su entorno.

He intentado, a lo largo de esta exposición, hacer un rápido repaso del impacto ambiental de la industria del cemento, así como de los principales problemas que plantean a esta actividad la puesta en marcha de una política de protección del medio ambiente.

Hasta ahora, la industria era bien acogida en cualquier comunidad con tal de que creara suficientes puestos de trabajo. Hoy en día las comunidades se han vuelto más exigentes y piden un ambiente sano y limpio, estando incluso dispuestas a renunciar a los beneficios de la industrialización con tal de proteger su medio ambiente.

Los empresarios deben ser plenamente conscientes de que existen corrientes de opinión actualizadas sobre los derechos de la comunidad a administrar su patrimonio ambiental y que empiezan a adoptarse nuevas posiciones en algunas áreas del país ante el proceso de industrialización. Los empresarios deben ser realistas a la hora de negociar la implantación de una industria con la comunidad que le dará acogida. Los empresarios deben evaluar previamente las consecuencias que sobre el medio ambiente ejercerá una nueva actividad. Afortunadamente han dejado de tener validez en la época actual las prácticas negociadoras de los primeros colonizadores de América con la población indígena en sus operaciones de trueque de oro por avalorios. Sólo así, sólo con una actitud noble y honrada, el empresario puede romper el maleficio que ha caído sobre la industria en aras de un ambiente puro, y mejorar su imagen ante la comunidad. La industria, en definitiva, debe estar en todo momento al servicio de la comunidad, evitando a toda costa que sea considerada como el cáncer de la Sociedad contemporánea. 
1. Abierto por el Presidente, Sr. ANASAGASTI, lo comenzó el Sr. PALAU, sobre el tema de la homologación de aparatos para la medida de la concentración de polvo. Creo - dijo-, que actualmente no existe en España una normativa definida, acerca de la homologación de estos aparatos; pero, por otra parte, parece que el Ministerio de Industria insiste en que las empresas estén dotadas de ellos para controlar su emisión de partículas sólidas. Existe entonces - continuó-, el riesgo de hacer inversiones en aparatos que, ya instalados, no superen las pruebas de homologación cuando salga la normativa, y ante tal riesgo las empresas se resisten a hacer inversiones en equipos que, aun sin estar amortizados, tendrían que ser sustituidos por otros homologados por el Ministerio. ¿Qué solución aporta éste - preguntó-, para vencer este temor que impide en la realidad una colaboración entre las empresas y la Administración?

Respondió el Sr. ENSEÑAT diciendo que, aunque no lo había mencionado en su exposición, el día 20 de octubre de 1976 se había enviado al Boletín Oficial del Estado una Disposición Ministerial que viene a ser el manual de una posible actuación conjunta del Ministerio y de los industriales, muy amplio en todos los aspectos, pues recoge experiencia del Plan Bilbao y de la puesta en práctica del Decreto 833, la cual ha permitido no sólo modificar éste, sino completarlo y aclararlo. La Disposición, con unas ochenta páginas de texto, toca, entre otros aspectos, el de la homologación de aparatos.

Para llevarla a cabo - continuó-, se precisa tener una experiencia y hay que hacer estudios serios del mercado internacional de aparatos, puesto que éstos no se hacen aquí ni se harán en unos años. A este respecto existe una disposición transitoria en la que se dice que el industrial va a poder elegir el tipo y marca de aparato que crea conveniente. $\mathrm{Y}$ cuando lo haga de buena fe y la marca esté homologada en países con experiencia y serios en cuanto al tema - como Estados Unidos, Alemania, Francia o Japón por ejemplo (pues Inglaterra importa los aparatos) -, el industrial no va a tener dificultades para homologar su aparato en España, cuando salgan las normas correspondientes y sean designados los laboratorios oficiales para el caso. Porque -aclaró-, no es cosa de enmendar la plana a los sistemas de homologación de estos países.

Sí habrían de ser sustituidos, en cambio, aparatos sin fiabilidad ni respaldo científico; por lo cual - prosiguió-, yo aconsejaría que los aparatos que se adquieran vengan con el certificado de homologación del país de origen para que, al ser publicada la Orden sobre Prevención y Corrección de la Contaminación Industrial de la Atmósfera -que desarrolla el Decreto 833 en lo que afecta al Ministerio de Industria-, no haya dificultad en computar la homologación de origen, con lo cual no existe riesgo para las inversiones previas.

2. A continuación el Sr. PALOMAR LLOVET pidió una aclaración y expuso una opinión. La aclaración que pido - dijo-, es que se ha hablado de una encuesta sobre emisión de polvo hecha en fábricas de cemento, con una respuesta muy positiva y dada de buena fe, y con unos resultados que, a la vista de los valores consignados, eran muy favorables, comparados con los de la industria en general. Pues bien —continuó-, me ha parecido entender que esos resultados han causado extrañeza al ser cotejados con los co- 
rrespondientes de la industria del cemento británica. Y no lo he podido comprender - prosiguió-, porque me consta que la industria española del cemento, tal vez sólo por haberse desarrollado en los últimos años, posee unas instalaciones muchísimo más modernas y adelantadas que la industria inglesa, que tiene fábricas muy anticuadas en las que, con una sola excepción, prácticamente no se ha hecho ni renovado ninguna instalación en los últimos tiempos. Y al ser esto así —concluyó-, no entiendo cómo se puede decidir que unos datos españoles sobre una encuesta son rechazables porque superan en bondad a los correspondientes ingleses. Me gustaría que se me aclarase este punto y luego daré mi opinión sobre el problema del polvo en conjunto - terminó el Sr. PALOMAR-.

Respondió el Sr. ENSEÑAT diciendo que no había dicho ni pensaba que el cuestionario hubiese sido cumplimentado de mala fe pero que consideraba que éste era difícil, y que como tal se había manifestado para el 99 por ciento de los industriales de todos los sectores. Y que los datos de una segunda encuesta le habían sorprendido mucho más aún, pues parece que daban a entender que, partiendo de los niveles de emisión que la legislación fija, se habían hecho cálculos hacia atrás, y que al rehacer éstos a partir de la emisión declarada, conducían a los $400 \mathrm{mg} / \mathrm{m}^{3} \mathrm{~N}$ de polvo. Pero con independencia de esto - prosiguió-, lo que quiero decir es que, al comentar estos resultados con expertos de este tipo de encuestas, y con responsables de la contaminación de diversos países me han venido a decir que suponían que no me habrían servido de nada las contestaciones, porque es muy difícil cumplimentar correctamente la encuesta. Es decir - continuó-, que tal dificultad no es algo privativo de España, sino que tiene carácter general, y en tal sentido quisiera que no hubiera malos entendidos en cuanto a que nunca se ha pensado en que haya podido haber mala fe en las respuestas al cuestionario; puede haber habido, eso sí, malas interpretaciones, bien hayan sido del cuestionario, o bien de las respuestas al mismo.

Lo que puedo citar también en relación con la industria inglesa — siguió diciendo el Sr. ENSEÑAT-, es el auténtico milagro, mucho mayor que el del propio Londres, que se aprecia en cualquier actividad industrial de algunas áreas del país con relación a los resultados de la lucha contra la contaminación, y en industrias en las que no era rentable la lucha. En tal sentido -continuó-, la industria inglesa del cemento puede que sea antigua, pero es evidente que se han gastado muchos millones - como había puesto en evidencia en una de las tablas de su exposición-, y tal vez más todavía por el hecho de serlo, para combatir la contaminación. Ruego al Sr. PALOMAR - concluyó el Sr. ENSEÑAT-, que insista en lo que considere que no ha sido contestado adecuadamente.

El Sr. PALOMAR dijo que la comparación le había parecido desproporcionada en relación con el esfuerzo que había hecho la industria española durante estos años. Quizás -aclaró-, por tratarse de una industria que no cuida mucho de su imagen pública, no se ha dado a conocer nada - a diferencia de lo sucedido en otras industrias- sobre la incidencia de las inversiones en la captación de polvo. Entonces -y ahora es cuando paso a expresar la opinión de que hablaba (dijo) -, entiendo que estas cuestiones son muy delicadas, dado el sistema especial establecido sobre la contaminación en España, el cual deja desamparada a la industria. Si hubiera que tratar sólo con el Ministerio del ramo -aclaró-, no había problema, ni siquiera con una legislación que fuese la más dura de Europa, porque se harían las inversiones necesarias en el tiempo preciso, las cuales se tendrían en cuenta al establecer el nuevo precio. Lo peor es el desamparo frente a posturas demagógicas contra todo lo que significa empresa. Citó el caso de urbanizaciones hechas - posiblemente especulando con el suelo- alrededor de cualquier fábrica de cemento establecida desde antiguo, y contra la que se va porque "echa polvo", tal como se trata de demostrar con muestras tomadas de cualquier manera, y a veces hasta con acta notarial, todo lo cual se airea en los medios informativos. Y lo malo es también -continuó el Sr. PALOMAR-, que el fallo o decisión depende de una autoridad local, honesta pero no técnica, posiblemente más relacionada con los responsables de la urbaniza- 
ción que con el consejo de administración de la fábrica de cemento. Al estar establecido así, la empresa cementera está a la intemperie y nada puede hacer por evitarlo, cuando lo lógico sería que estos asuntos los llevase el Ministerio de Industria que, como protector de la pureza del medio ambiente legisla, y podría medir las emisiones de polvo y dictaminar con autoridad técnica y sin apelación. Creo - concluyó-, que valdría la pena que el Ministerio de Industria, que comprende el problema, al habla con el de Gobernación plantease y resolviese éste, dando al setor cementero la oportunidad de defenderse contra acciones injustificadas que pueden llegar - dijo-, a provocar el cierre de empresas con grandes capitales invertidos.

El Sr. ENSEÑAT se manifestó de acuerdo con todo lo expuesto y dijo que también al Ministerio le preocupaba la demagogia que hace que no exista suelo industrial en el país. Citó el caso típico y actual, dado a conocer por la prensa, de una industria que en Bilbao llevaba gastados bastantes millones en su montaje y a la que le han parado las obras y le han retirado la autorización; pero que, resignada a las pérdidas y tratando de buscar otro emplazamiento, no lo encuentra por la mala prensa que le han hecho, injustificadamente y por desconocimiento de algunos medios de información. Se da el caso, también en Bilbao -añadió-, de haber denegado autorización a una industria de producción de plaguicidas por presión de la opinión pública a la que este nombre asusta; mientras que dicha empresa ha sido acogida en Inglaterra, y subvencionada oficialmente en un $25 \%$ por su esfuerzo en pro del medio ambiente. Esto - dijo-, es grave y lamentable en un país que empieza a presumir de desarrollo, y exige luchar contra la demagogia existente, tal vez mediante contactos de la Administración, no ya sólo con los sectores industriales, sino también con los medios de información, porque donde no hay comunicación, no puede haber entendimiento. $\mathrm{Y}$, por supuesto que también - prosiguió-, instruyendo a la gente y concienciando equilibradamente no sólo como hasta ahora a quien tiene más capacidad crítica y demagógica que resolutiva, sino también, y antes, a la inversa.

$\mathrm{Y}$ todo esto me hace pensar — continuó diciendo el Sr. ENSEÑAT-, en la importancia que tendrá el preparar un seminario análogo al de la FEANI (Federación Europea de Asociaciones Nacionales de Ingenieros), al que asistí como representante del Instituto de Ingenieros Civiles de España, y en el que se trató de la formación y puesta al día, en todas las etapas y a todos los niveles, de los ingenieros en el terreno de la contaminación y de la protección del medio ambiente. En esta línea y por parte del Fondo de las Naciones Unidas para el Medio ambiente, de la UNESCO, se ha establecido una especie de Código de Etica Profesional del Ingeniero, para que éste, por sí mismo o ayudado por colegas competentes en la materia, pueda medir el impacto ambiental de sus proyectos y corregir lo que haga falta para minimizar dicho impacto. Esto es necesario, porque la sociedad quiere alguien que se responsabilice de lo que hace, y alguien que diagnostique con fiabilidad si lo que se hace se está haciendo bien o mal, para evitar el gran daño que a causa de un dictamen equivocado, incluso de buena fe, puede una sola industria hacer a todo el resto de un sector. Y porque esa misma sociedad —prosiguió-, quiere que alguien que conozca el problema de la contaminación y sepa explicarlo, lo haga con franqueza y de forma comprensible.

Y por lo que se refiere al tema de las urbanizaciones - siguió diciendo el Sr. ENSEÑAT-, en efecto he visto en sectores afines al campo de la química fotografías de industrias solitarias y aisladas hace veinte años y rodeadas hoy de viviendas por todas partes, las cuales se quejan de un vecino incómodo. Para cortarlo -agregó-, no hay más que dos soluciones: o la industria establece una servidumbre comprando terreno "para poder contaminar sin molestar a nadie, ni que a su vez nadie le moleste", o llevar a cabo por parte de la Administración una política bien concebida y coordinada para la ordenación del territorio. Pues sin esa política no es posible impedir la construcción de viviendas junto a industrias, si éstas no han adquirido previamente la servidumbre. Es, pues, necesario establecer, como en otros países, una separación entre zonas residencia- 
les, zonas de viviendas, zonas comerciales, zonas industriales, etc., y hacerlo bien; porque parece absurdo que se esté desarrollando una zona industrial en contra del viento que llega a Madrid, cuando debiera desarrollarse a favor, es decir, "vientos abajo" de la cuenca atmosférica de la zona, para evitar el vertido de humos, gases y polvo y contaminantes en general.

Concluyó el Sr ENSEÑAT diciendo que quería insistir en que todos los sectores deben esforzarse en mejorar la panorámica, pero que, desgraciadamente, la legislación establıcida para otorgar incentivos fiscales, conceder créditos en condiciones ventajosas, e incluso subvenciones, ha tenido un desarrollo muy escaso, y que tales ayudas deberían tenerlo amplio; y, asimismo, que el Ministerio de Industria en tal sentido ha negociado con el Banco Mundial sobre la posibilidad de que financiara una parte del plan Bilbao, como única salida para resolver el problema en dicha ciudad y zona. En definitiva, - concluyó-, se hace lo que se puede para no producir colapsos a las industrias, y con estos comentarios — dijo-, respondo a los comentarios del Sr. PALOMAR.

3. El Sr. DANEYKO preguntó después si en el nuevo Decreto se tenían en cuenta las circunstancias accidentales. Aclaro la pregunta diciendo que las normas sobre contaminación con polvo se refieren al funcionamiento normal de las fábricas; pero que existen situaciones extraordinarias o anormales, como son la puesta en marcha después de una parada prolongada o la avería de los elementos de captación de polvo, etc., y quería saber si ello estaba previsto y había sido tomado en consideración.

Le respondió el Sr. ENSEÑAT diciendo que, efectivamente, estaba previsto en las disposiciones sobre nuevos niveles de emisión, sobre modificación de plazos, e incluso sobre tolerancias. Por ejemplo — dijo-, ante la premura de tener que hacer una medición de polvo y la inseguridad de hacerla con la misma precisión que se haría en un laboratorio, se dan unas tolerancias muy amplias, que a veces pueden llegar incluso al 30 o al $40 \%$ sobre el valor previsto. Y cuando se rebasen estas tolerancias, y según el grado de rebasamiento, se hacen otras mediciones con mayor duración de la toma de muestra, e incluso con prolongación del período de prueba, precisamente porque de lo que se trata es de no perjudicar por causas accidentales o fortuitas.

$\mathrm{Y}$, finalmente, al no haber más preguntas sobre el tema, dando las gracias al ponente y a los participantes en el Coloquio, éste fue cerrado por el Presidente, Sr. ANASAGASTI. 